\title{
Experimental Study on the Motion Response and Mooring Characteristics of a New Type Deep-draft Multi-column FDPSO
}

\author{
Xuncheng Tu, Xianghong Huang, Chunyang Zhao
}

\begin{abstract}
Considering the effect of wave period, wave height and wave angle, an experimental study for the motion response and mooring characteristics of a new type deep-draft multi-column FDPSO in $1500 \mathrm{~m}$ operation water depth, was conducted in State Key Laboratory of Ocean Engineering (SKLOE) of Shanghai Jiaotong University. Taking account of water depth limitation of the deep-draft offshore basin and arrangement characteristics of mooring system, a $300 \mathrm{~m}$ equivalent water depth truncated mooring system was designed. The results show that the FDPSO's 6-DOFs motion responses except yaw present sinusoidal variation under exci-tation of regular waves, as well as the response of mooring lines' tension. The wave angle has a relatively small effect on surge, pitch and heave, while sway and roll are sensitive to the change of wave angle, and yaw of the platform is very weak. At the same time, the tension of mooring lines increases with the improvement of sea condition, while the distribution of mooring lines under maximum tension is closely connected with wave angle. The mooring system strength satisfies the design requirements after verification.
\end{abstract}

Index Terms - model test; equivalent water depth trunca-tion; motion response; mooring characteristic

\section{INTRODUCTION}

With energy demand rising, the future development of oil and gas exploration will be transferred to deep-draft area. Much exploration will be saved by using FDPSO (Floating Production Drilling Storage \& Offloading) in early phases of exploration. Pilot production on different areas determines reasonable scale and pattern of production. The use of FDPSO can improve the production efficiency in some areas where we do not have a fully understanding of reservoir conditions. For the development of deep water oil and gas exploitation, studying the motion response and mooring characteristics of FDPSO is great significant.

The scale of existing basin is not satisfied to the experiment requirements of deep-draft platform's full depth mooring system. Stansberg[1] introduced two methods to solve this problem, passive hybrid model test technique and active hybrid model test technique, and the former is more widely applied. Baarholm[2] carried out the equivalent truncated water depth mooring experiment for a deep-draft semi-submersible platform. The numerical simulation results

Xuncheng Tu Postgraduate of Naval Architecture and Ocean Engineering department of Jiangsu University of Science and Technology, China. +8618344815748

Xianghong Huang Phd of Harbin Engineering University, China. $+8618706100669$

Chunyang Zhao Postgraduate of Naval Architecture and Ocean En-gineering department of Jiangsu University of Science and Technology, China.+8618796087050 calculated by the time domain coupling analysis method showed good agreement with the experimental results. Taking into account the ratio of wave length to ship length is 0.5-2.0 and the ratio of wave frequency to wave length is constant, Munipalli[3] carried out the experimental study on the motion response under effect of weather vane for a FPSO with internal turret mooring system, which adopted 1:60 scale ratio. Vijayalakshmi[4] dealed with experimental and numerical computation analysis of the motion response of the FPSO of the floating tank bottom with additional horizontal damping plates. Soares[5] measured six degree of freedoms motion response and mooring force of a FPSO in regular waves and random waves by experiments, and the results calculated by Green function method are in good agreement with the experimental results. Considering two different loading conditions, Torres[6] carried out an experiment on motion response of a FPSO in $1000 \mathrm{~m}$ water depth in regular wave and random wave by passive hybrid model test technique. The experimental results show that the horizontal movement (surge) in random wave reached twice as response in regular wave. Wei[7,8] researched hydrodynamic performance of ship style FDPSO operating in the South China Sea China, considering different sea conditions and different incident wave angle. The model test and numerical simulation were combined to analysis of the motion mode. Study found that the wave frequency characteristic is dominant to the vertical motion and the horizontal movement is mainly affected by second-order wave force. Sun[9] designed a grouped equal angle tension mooring system for a $2000 \mathrm{~m}$ depth octagonal shaped single column FDPSO. The numerical calculation is carried out through the linear frequency domain analysis method, and results shows that the displacement of the platform under various working conditions meets the requirement. In addition, the domestic scholars proposed some new design concepts of FDPSO, such as Wei[10] ,Li [11] and Zhao[12] etc. They carried out the research on the hydrodynamic performance and mooring characteristics on the basis of the conceptual design.

In this paper, an experiment on the motion response and mooring characteristics of a new type FDPSO in regular wave is carried out in the deep ocean engineering Shanghai Jiao Tong University laboratory, combining its general design and considering the coupling effect between the platform and the mooring system. Besides, the different wave period, wave height and wave angle are taken into account, and the method of equivalent truncated mooring design is used in this experiment. The research on 6-DOF motion time history curve, time domain characteristics of cable tension and cable strength are paid close attention to. This paper aims to provide some reference for the design of multi-column FDPSO. 


\section{STRUCTURE CHARACTERISTICS OF FDPSO AND ARRANGEMENT OF THE EQUIVALENT TRUNCATION MOORING SYSTEM}

The main body of this new type multi-column FDPSO is composed of an octagonal pontoon and four variable cross sections columns. The main dimensions and hydrodynamic parameters of the platform are shown in Tab.1. The general arrangement is show in Fig.1.

\begin{tabular}{|c|c|c|c|c|c|}
\hline Designation & Unit & Parameters & Designation & Unit & Parameters \\
\hline Length & $\mathrm{m}$ & 81.8 & $\begin{array}{l}\text { width of pontoon under the } \\
\text { column }\end{array}$ & $\mathrm{m}$ & 20.02 \\
\hline Width & $\mathrm{m}$ & 81.8 & $\begin{array}{l}\text { width of pontoon between } \\
\text { columns }\end{array}$ & $\mathrm{m}$ & 19.056 \\
\hline Depth & $\mathrm{m}$ & 76.5 & Pontoon height & $\mathrm{m}$ & 10.92 \\
\hline Maximum working depth & $\mathrm{m}$ & 1500 & $\begin{array}{l}\text { Longitudinal center of } \\
\text { gravity position }\end{array}$ & $\mathrm{m}$ & $0 / 0$ \\
\hline Draft & $\mathrm{m}$ & 59.15 & $\begin{array}{l}\text { Vertical center of gravity } \\
\text { position }\end{array}$ & $\mathrm{m}$ & 25.52 \\
\hline Displacement & $\mathrm{t}$ & 119,660 & Inertia radius of pitching & $\mathrm{m}$ & 31.84 \\
\hline Total height of column & $\mathrm{m}$ & 64.08 & Inertia radius of roll & $\mathrm{m}$ & 30.56 \\
\hline Bottom diameter of column & $\mathrm{m}$ & 20.02 & Inertia radius of yaw & $\mathrm{m}$ & 32.4 \\
\hline
\end{tabular}

Tab.1 Main dimensions and hydrodynamic parameters of FDPSO
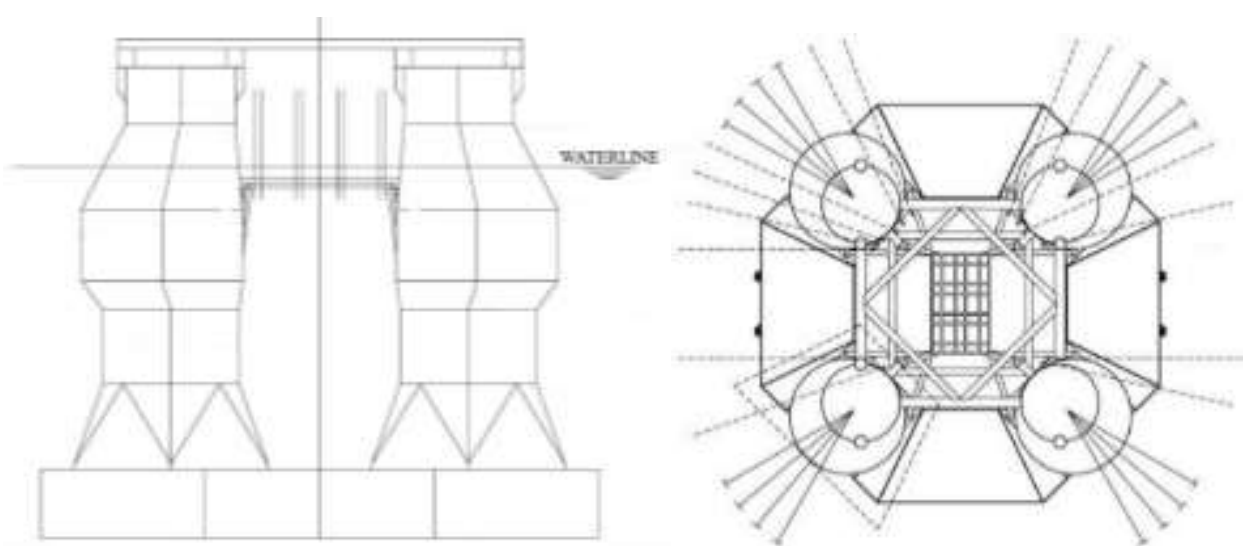

Fig.1 General arrangement of the FDPSO

The variety of mooring systems is used on platform currently. Multi-leg mooring system ${ }^{[13]}$ is adopted on multi-column FDPSO. The system is composed of 4 groups of chains. Every group consists of 4 chains, and 16 chains in all. Interval angle of each chain in every group is 5 degrees. The composition of mooring system is chain-cable-chain. The arrangement of mooring system is shown in Fig.2.The parameters of mooring system design are shown in Tab. 2 .

The actual operating water depth of platform is 1500 . Distance between fairleader and waterline is $51.5 \mathrm{~m}$, which has exceeded the scale of deep-draft offshore basin even with
1:80 scale factor. Therefore, the method of equivalent truncation design ${ }^{[14,15]}$ is applied to FDPSO's mooring system. The vertical truncation coefficient is 5.0. The parameters of equivalent truncated mooring system are shown in Tab.3.

Fig. 3 shows the force characteristics of mooring system before and after truncation. The comparison shows the horizontal restoring force and top tension of single chain of mooring system both fit together before and after truncation. Therefore, the truncated water depth design is quite effective in simulating dynamic response of the platform.

Tab.2 Design parameters of the mooring lines

\begin{tabular}{ccccccc}
\hline Designation & Length & Diameter & Weight in air & Submerged Weight & Axial stiffness & Minimum breaking load \\
Unit & $\mathrm{m}$ & $\mathrm{mm}$ & $\mathrm{kg} / \mathrm{m}$ & $\mathrm{kg} / \mathrm{m}$ & $\mathrm{kN} / \mathrm{m}$ & $\mathrm{kN}$ \\
\hline Chain & 2514 & 127 & 321.86 & 279.82 & $1,623,600$ & 14,955 \\
Polyester & 319 & 262 & 42.44 & 10.57 & 468,396 & 17,348 \\
\hline
\end{tabular}


International Journal of Engineering and Applied Sciences (IJEAS)

ISSN: 2394-3661, Volume-5, Issue-9, September 2018

Tab.3 Parameters of the mooring line in truncated model

\begin{tabular}{|c|c|c|c|c|c|c|c|c|}
\hline \multirow[b]{2}{*}{ Designation } & \multicolumn{2}{|c|}{ Length } & \multicolumn{2}{|c|}{ Submerged Weight } & \multicolumn{2}{|c|}{ Axial stiffness } & \multicolumn{2}{|c|}{ Pre-Tension } \\
\hline & $\begin{array}{c}\text { Prototype } \\
\text { (m) }\end{array}$ & $\begin{array}{c}\text { Model } \\
(\mathrm{m}) \\
\end{array}$ & $\begin{array}{c}\text { Prototype } \\
\text { kg/m }\end{array}$ & $\begin{array}{l}\text { Model } \\
(\mathrm{kg} / \mathrm{m})\end{array}$ & $\begin{array}{c}\text { Prototype } \\
(\mathrm{kN} / \mathrm{m})\end{array}$ & $\begin{array}{l}\text { Model } \\
(\mathrm{N} / \mathrm{cm})\end{array}$ & $\begin{array}{c}\text { Prototype } \\
(\mathrm{kN})\end{array}$ & $\begin{array}{c}\text { Model } \\
(\mathrm{kN}) \\
\end{array}$ \\
\hline Chain & 60 & 0.750 & 279.82 & 0.0426 & $1,623,600$ & 0.238 & & \\
\hline Polyester & 262.395 & 3.280 & 10.57 & 0.0206 & 468,396 & 41.895 & 3754.27 & 0.7295 \\
\hline Chain & 80 & 1.000 & 279.82 & 0.0426 & $1,623,600$ & 0.318 & & \\
\hline
\end{tabular}

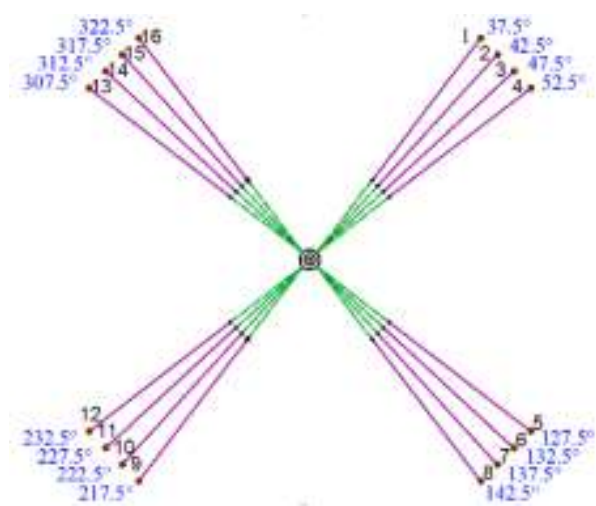

Fig.2 Arrangement of the mooring lines

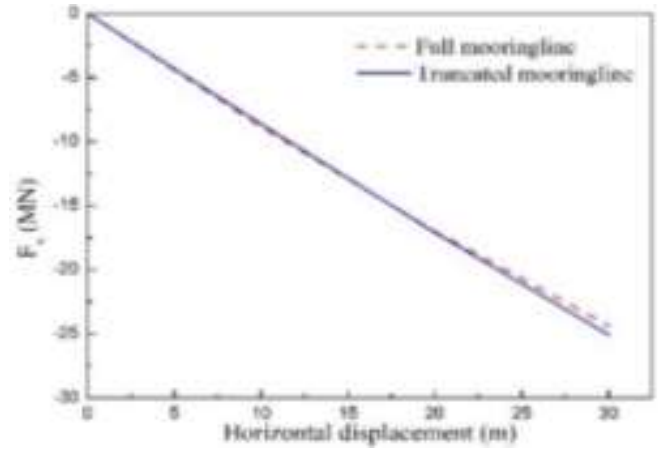

(a) Horizontal restoring force

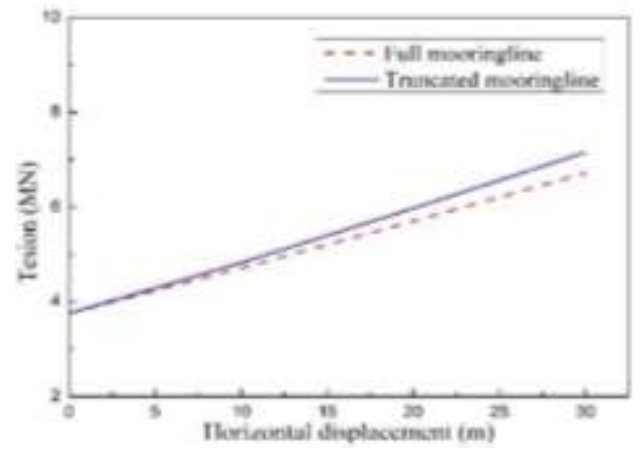

(b) Top tension of single anchor

Fig.3 Force characteristics of mooring system before and after truncation

\section{EXPERIMENTAL MODEL AND CONDITIONS}

The main body of the experimental model is a hollow structure to facilitate the adjustment of weight and center of gravity. In order to obtain the hydrodynamic parameters accurately, correct adjustment of displacement, the center of gravity and inertia radius is particularly important.
Adjustment of displacement is realized by loading weight, and the position of gravity center and inertia are adjusted through special adjusting frame in laboratory [16].

In the experiment, considering three kinds of sea conditions and two kinds of wave angle, there are six cases in total. The experimental conditions are shown in Tab.4. The experiment in Deep-draft Offshore Basin is shown in Fig.4.

Tab.4 Load case of experiment

\begin{tabular}{ccccc}
\hline Case number & Wave angle & Wave period (s) & Wave height $(\mathrm{m})$ & Condition identification \\
\hline 1 & $0^{\circ}$ & 10.91 & 5.22 & Regular Wave 1_0deg \\
2 & $45^{\circ}$ & 10.91 & 5.22 & Regular Wave 1_45deg \\
3 & $0^{\circ}$ & 16.55 & 11.75 & Regular Wave 2_0deg \\
4 & $45^{\circ}$ & 16.55 & 11.75 & Regular Wave 2_45deg \\
5 & $0^{\circ}$ & 22.32 & 20.88 & Regular Wave 3_0deg \\
6 & $45^{\circ}$ & 22.32 & 20.88 & Regular Wave 3_45deg \\
\hline
\end{tabular}




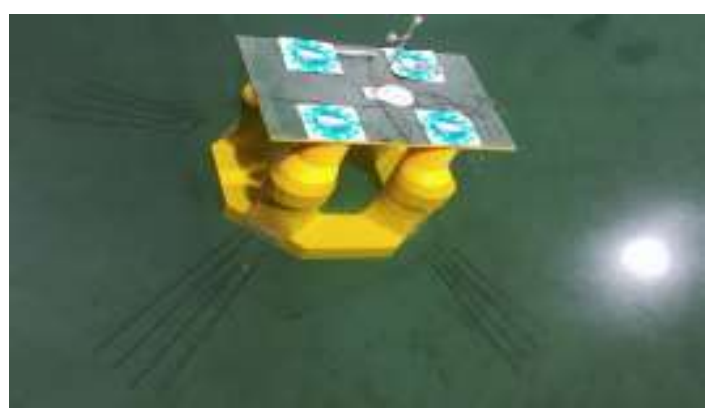

Fig.4 Regular waves experiment of

IV. MOTION RESPONSES AND MOORING CHARACTERISTICS OF FDPSO

\section{A. Natural period and dimensionless damping coefficient of the FDPSO}

In the free decay experiments of the platform, the force is exerted upon FDPSO on direction of 6-DOFs respectively. The platform recovered to original balancing position under static restoring moment. The natural period and amplitude of 6-DOFs motion were collected by the data acquisition system, which were analyzed to obtain damping coefficient of this platform. The natural period and damping coefficients of FDPSO are shown in table 5.

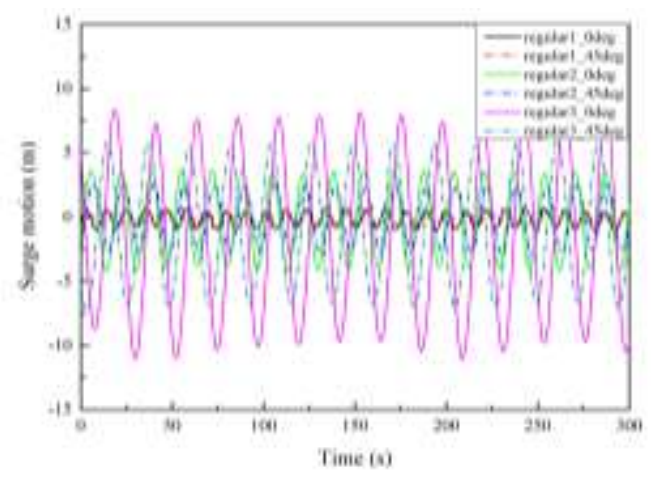

5(a) surge

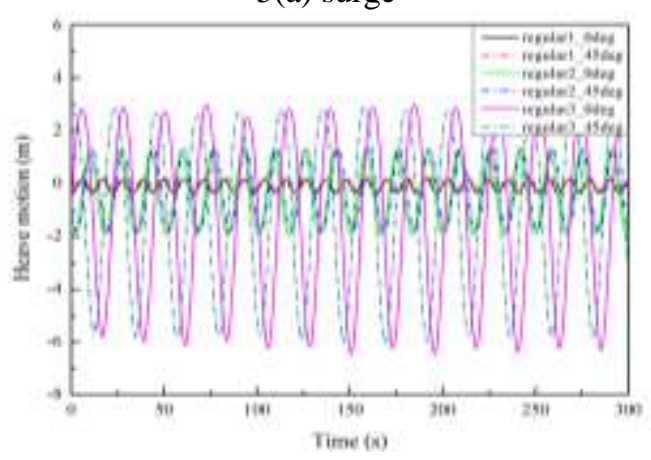

5(c) heave

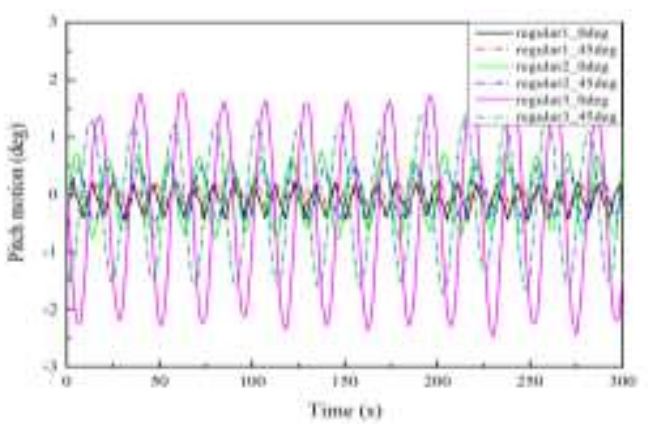

5(e) pitch

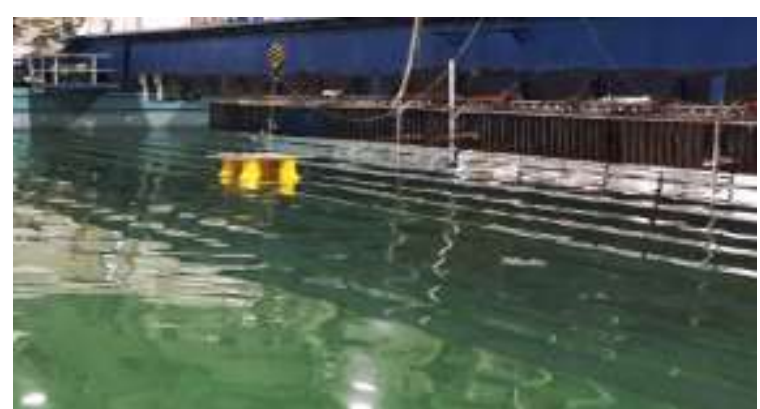

FDPSO in Deep-draft Offshore Basin

Tab.5 Natural period and dimensionless damping coefficient of FDPSO

\begin{tabular}{ccccccc}
\hline Designation & Surge & Sway & Heave & Roll & Pitch & Yaw \\
\hline $\begin{array}{c}\text { Natural period } \\
(\mathrm{s})\end{array}$ & 99.11 & 99.11 & 24.29 & 34.96 & 34.96 & 7.36 \\
$\begin{array}{c}\text { Dimensionless } \\
\text { damping } \\
\text { coefficient }\end{array}$ & 0.0352 & 0.0352 & 0.0144 & 0.0219 & 0.0219 & 0.0183 \\
\hline
\end{tabular}

\section{B. Analysis of motion response}

According to the range of location parameter of the main and side hull as determined above, the scheme shown in Table II is set up.

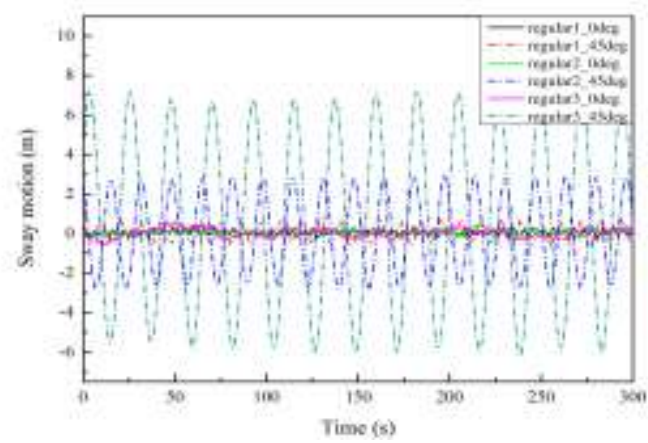

5(b)sway

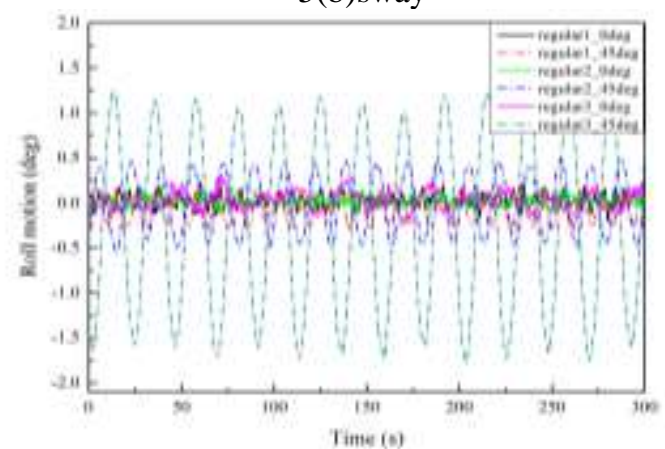

$5(d)$ roll

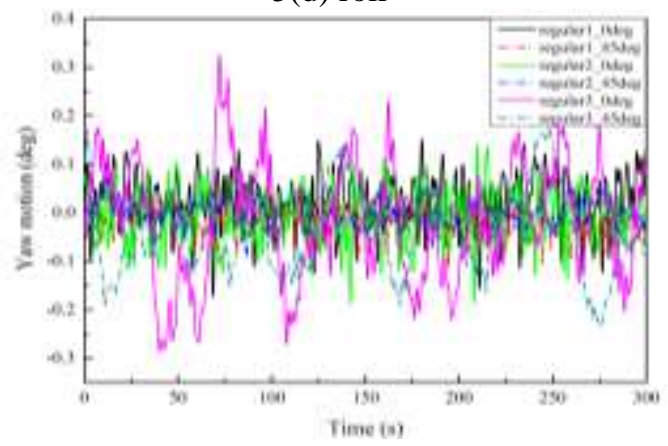

5(f) yaw

Fig.5 Time series of the motion responses for the FDPSO 
The time series of the motion responses for the Multi-column FDPSO are shown in Fig.5. Above all, under regular wave excitation, 6-DOFs motion response except yaw show favorable regularity. The motion response amplitudes of platform increase with the enhancement of sea conditions.

In three sea conditions, fig.5(a) shows that surge amplitude at $0^{\circ}$ wave angle is slightly larger than that at $45^{\circ}$ wave angle. When the wave period is $22.32 \mathrm{~s}$ and the wave height is $20.88 \mathrm{~m}$, the surge amplitude is $11.07 \mathrm{~m}$ and $7.36 \mathrm{~m}$ at $0^{\circ}$ and $45^{\circ}$ wave angle respectively. It can be found that motion response amplitude of surge and sway are consistent in every case by comparing fig.5(a) and fig.5(b), and the similar regular pattern are found in roll and pitch. For instance, in case 5 , surge amplitude is $7.36 \mathrm{~m}$, close to $7.28 \mathrm{~m}$ of sway, and pitch amplitude is $1.72^{\circ}$ which is near to $1.78^{\circ}$ of roll. This is caused by favorable structural symmetry of the Multi-column FDPSO.
Fig.5(c) shows negative maximum displacement of heave is $3.0 \mathrm{~m}$, while positive maximum heave displacement jumped 2.16 times to $6.48 \mathrm{~m}$ dramatically. This gap of displacement also increases with the enhancement of sea condition, which is determined by mooring characteristic. Mooring lines is in tension state when the platform moves upward, and the restoring force increases with the upward displacement. The platform shows contrary when it has a motion of downwards, and this phenomenon is not obvious in sea conditions of small wave height, but it should be paid enough attention in high sea conditions.

As shown in fig.5(d), fig.5(e) and fig.5(f), the amplitude of roll, pitch and yaw is quiet small, accounting for $1.78^{\circ}, 2.46^{\circ}$ and $0.33^{\circ}$. This new FDPSO shows very good movement performance on these freedoms. Statistics of 6-DOFs motion response are shown in Tab.6.

Tab.6 Statistics of 6-DOFs motion response

\begin{tabular}{|c|c|c|c|c|c|c|c|c|c|c|c|c|c|}
\hline \multirow{2}{*}{$\begin{array}{c}\text { Tab.6 Statistics } \\
\text { of 6-DOFs } \\
\text { motion }\end{array}$} & \multirow{2}{*}{$\begin{array}{l}\text { Wave } \\
\text { angle }\end{array}$} & \multicolumn{4}{|c|}{ Regular1 } & \multicolumn{4}{|c|}{ Regular2 } & \multicolumn{4}{|c|}{ Regualr3 } \\
\hline & & Max & Min & Mean & STD & Max & Min & Mean & STD & Max & Min & Mean & STD \\
\hline \multirow{2}{*}{ surge(m) } & $0^{\circ}$ & 0.74 & -1.08 & & 0.54 & ד. & & & 2.03 & 0.70 & 11.0 & & 6.46 \\
\hline & $45^{\circ}$ & 0.49 & -0.74 & -0.14 & 0.41 & 2.73 & -2.91 & -0.11 & 1.85 & 6.21 & -7.36 & -0.68 & 4.54 \\
\hline \multirow[b]{2}{*}{ sway (m) } & $0^{\circ}$ & 0.40 & -0.35 & 0.06 & 0.10 & 0.52 & -0.31 & 0.08 & 0.15 & 0.65 & -0.60 & 0.06 & 0.23 \\
\hline & $45^{\circ}$ & 0.76 & -0.67 & 0.03 & 0.40 & 2.96 & -2.79 & 0.07 & 1.95 & 7.28 & -6.22 & 0.60 & 4.52 \\
\hline \multirow[b]{2}{*}{ heave(m) } & $0^{\circ}$ & 0.16 & -0.39 & -0.10 & 0.18 & 1.26 & -1.97 & -0.39 & 1.09 & 3.00 & -6.48 & -1.29 & 3.26 \\
\hline & $45^{\circ}$ & 0.27 & -0.34 & -0.03 & 0.19 & 1.41 & -1.88 & -0.29 & 1.12 & 2.95 & -6.08 & -1.19 & 3.11 \\
\hline \multirow{2}{*}{ pitch(deg) } & $0^{\circ}$ & 0.27 & -0.49 & -0.11 & 0.19 & 0.76 & -0.76 & 0.01 & 0.46 & 2.10 & -2.46 & -0.22 & 1.40 \\
\hline & $45^{\circ}$ & 0.25 & -0.26 & 0.02 & 0.14 & 0.53 & -0.49 & 0.03 & 0.31 & 1.44 & -1.72 & -0.12 & 1.00 \\
\hline \multirow[b]{2}{*}{ roll(deg) } & $0^{\circ}$ & 0.23 & -0.20 & 0.03 & 0.07 & 0.20 & -0.23 & 0.02 & 0.06 & 0.42 & -0.25 & 0.05 & 0.11 \\
\hline & $45^{\circ}$ & 0.20 & -0.31 & -0.05 & 0.15 & 0.53 & -0.55 & 0.00 & 0.32 & 1.38 & -1.78 & -0.19 & 0.99 \\
\hline \multirow[b]{2}{*}{ yaw(deg) } & $0^{\circ}$ & 0.16 & -0.17 & 0.03 & 0.05 & 0.15 & -0.19 & -0.01 & 0.05 & 0.33 & -0.28 & -0.02 & 0.14 \\
\hline & $45^{\circ}$ & 0.06 & -0.11 & -0.02 & 0.03 & 0.08 & -0.10 & -0.01 & 0.03 & 0.20 & -0.30 & -0.03 & 0.09 \\
\hline
\end{tabular}

\section{Analysis of mooring characteristic}

In mooring system, the design strength of polyester cable is larger than that of steel chain, and its tension decreases with the increase of water depth. Therefore, the reliability of the mooring system is determined by tension safety factor of steel chain at fairlead. Tension characteristics of mooring system are shown in Fig.6.According to the specification [17] API-RP-2SK (2005), when used in quasi-static analysis, the safety factor of the anchor tension is 2.0. When used in the analysis of hydrodynamic performance, the safety factor of the anchor tension is 1.67 . In this experiment, hydrodynamic analysis is applied to the whole mooring system, so the safety factor is 1.67. Tab.7 gives the safety factor of No.1 anchor chain in all cases of maximum force.

Tab.7 Safety factor of No.1 mooring line

\begin{tabular}{ccccc}
\hline $\begin{array}{c}\text { Case } \\
\text { number }\end{array}$ & $\begin{array}{c}\text { Wave } \\
\text { angle }\end{array}$ & $\begin{array}{c}\text { Mooring lines } \\
\text { number }\end{array}$ & $\begin{array}{c}\text { Maximum } \\
\text { force }(\mathrm{kN})\end{array}$ & $\begin{array}{c}\text { Safety } \\
\text { factor }\end{array}$ \\
\hline 1 & $0^{\circ}$ & $\# 1$ & 3879.16 & 3.86 \\
2 & $45^{\circ}$ & $\# 1$ & 3838.67 & 3.90 \\
3 & $0^{\circ}$ & $\# 1$ & 4238.89 & 3.53 \\
4 & $45^{\circ}$ & $\# 1$ & 4287.78 & 3.49 \\
5 & $0^{\circ}$ & $\# 1$ & 5417.01 & 2.76 \\
6 & $45^{\circ}$ & $\# 1$ & 5598.61 & 2.67 \\
\hline
\end{tabular}

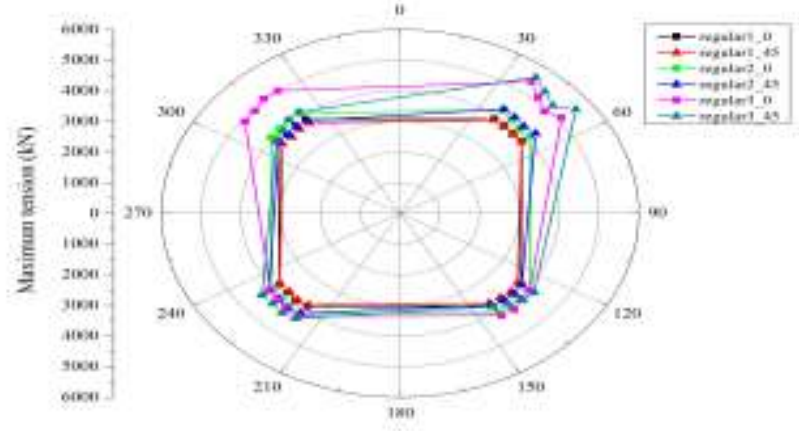

6 (a) The maximum value

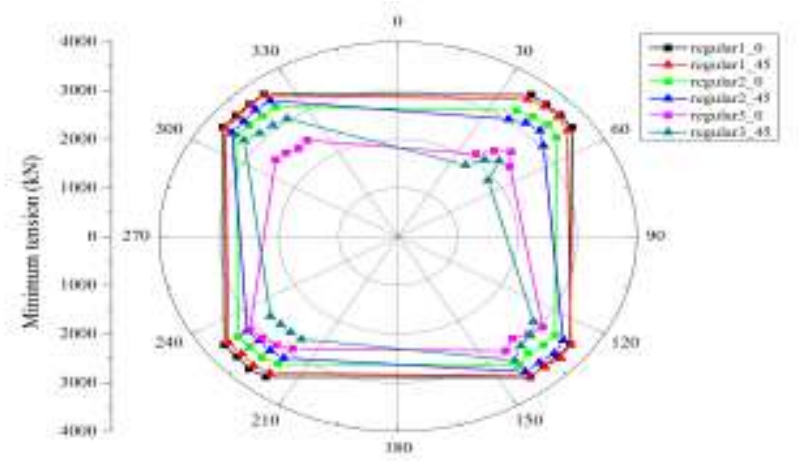

6 (b) The mininum value 


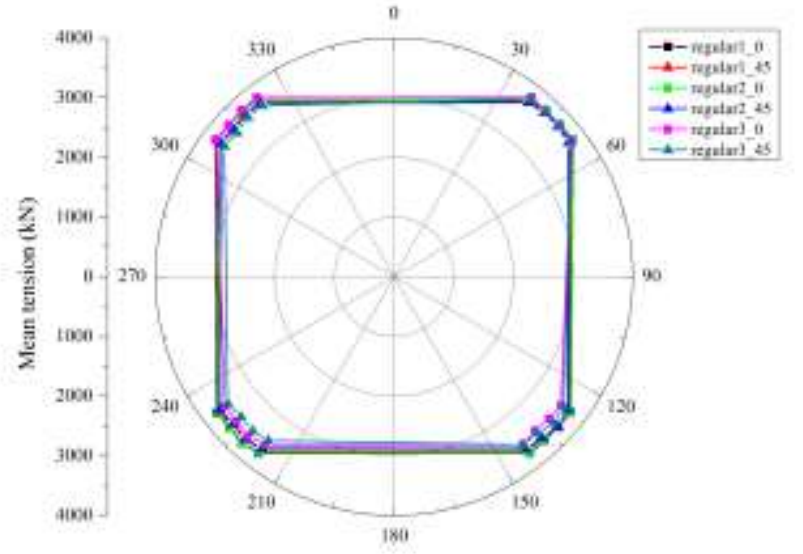

6 (c) The mean value

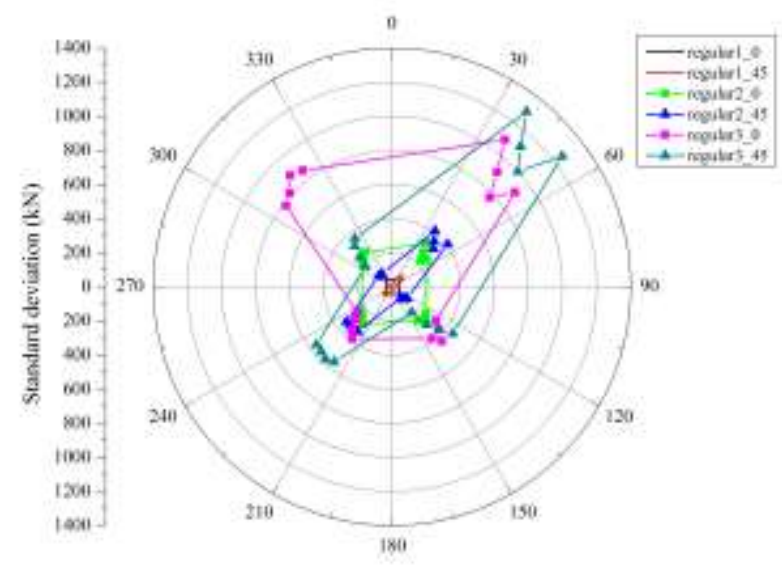

6 (d) The standard deviation

Fig.6 Tension characteristics of mooring system

Tension characteristics of mooring system are shown in Fig.6. As shown in fig.6(a), the maximum tension of upstream mooring lines is greater than that of downstream mooring lines, and an increasing trend of this difference is shown in the enhancement of wave period and wave height. When the wave period is $22.32 \mathrm{~s}$ and the wave height is $20.88 \mathrm{~m}$, the maximum tension of upstream mooring lines has been far greater than that of downstream mooring lines. In $45^{\circ}$ wave angle, the tension of \#5 \#8 and \#13 \#16 mooring lines are basically equal, and so as \#1 \#8 and \#9 \#16 mooring lines in $0^{\circ}$ wave angle. The mooring lines' tension increases with the enhancement of sea conditions. In case6, 1\# mooring line bears the strongest force accounting for $5598.6 \mathrm{kN}$. After verification, the safety factor is 2.67 , which is greater than the safety factor required to 1.67 by the standard. This shows the platform has high security.

As shown in Fig.6(b), the minimum tension falls with the increase of sea conditions, and the minimum tension of upstream mooring lines is lower than that of downstream mooring lines. This is the opposite of what is reflected in fig.6(a). Both this phenomenon and Fig.6(d) reveal that the fluctuation range of mooring lines' tension is enlarged with the increase of sea conditions, and the fluctuation of upstream is larger than that of downstream.

Overall, the tension of mooring lines is affected greatly by the wave period and wave height. The distribution of the mooring lines with maximum tension is closely related to the wave angle. Regardless of wave angle of $0^{\circ}$ or $45^{\circ}$, the mooring lines with maximum tension are located in the upstream region. Every situation of forced mooring line in each group is basically the same, except that force fluctuation range of \#2 and \#3 mooring line is relatively larger than the other two in each group, and the average tension value of mooring line is basically the same in each case.

\section{CONCLUSION}

Motion response of mooring system, tension of mooring lines and the safety factor of a new type deep-draft multi-column FDPSO in regular waves were studied. The experiment obtains results as follow:

1) The 6-DOFs motion response of the platform increases with the enhancement of sea conditions. The surge, sway and heave are impacted lightly by wave angle, and the maximum amplitude is $11.07 \mathrm{~m}, 7.28 \mathrm{~m}$ and $6.48 \mathrm{~m}$ respectively. However, this platform shows better movement performance on roll, pitch and yaw, which accounts for only $1.72^{\circ}, 1.78^{\circ}$ and $0.33^{\circ}$ to the maximum respectively.

2) In high sea conditions, the platform has significant larger heave displacement on negative than positive displacement. When the wave period is $22.32 \mathrm{~s}$ and wave height is $20.88 \mathrm{~m}$ in this experimental study, the negative displacement of heave jumped to 2.16 times than the positive displacement, this phenomenon should be paid enough attention in adverse sea conditions.

3) The tension value of chain is greatly affected by the sea condition. The distribution of the mooring lines with maximum tension is closely related to the wave angle. Regardless of wave angle of $0^{\circ}$ or $45^{\circ}$, the mooring lines with maximum tension are located in the upstream region. Every chain in other group gets same force basically except that force fluctuation range of \#2 and \#3 mooring line is relatively larger than the other two in each group.

4) The study found that all the safety factors of chain are larger than the standard requirements, and the strength of the mooring system meets the design requirements.

\section{REFERENCES}

[1] Stansberg C T, Ormberg H, Oritsland O. Challenges in Deep Water Experiments: Hybrid Approach[J]. Journal of Offshore Mechanics \& Arctic Engineering, 2002, 124(2):90-96.

[2]Baarholm R, Fylling I, Stansberg C T, et al. Model Testing of Ultra-Deep-draft Floater Systems: Truncation and Software Verification Methodology[C]//International Conference on Offshore Mechanics and Arctic Engineering. 2006: OMAE2006-92492.

[3] Munipalli J, Pistani F, Thiagarajan K P, et al. Weathervaning Instabilities of a FPSO in Regular Waves and Consequence on Response Amplitude Operators[C]//ASME 2007 26th International Conference on Offshore Mechanics and Arctic Engineering. American Society of Mechanical Engineers, 2007:405-412.

[4] Vijayalakshmi R, Panneerselvam R. Hydrodynamic response of a non-ship-shaped FPSO vessel with damping plates[J]. Journal of Marine Science \& Technology, 2012, 17(2):187-202.

[5] Soares C G, Fonseca N, Pascoal R. Experimental and Numerical Study of the Motions of a Turret Moored FPSO in Waves[J]. Journal of Offshore Mechanics \& Arctic Engineering, 2005, 127(3):197-204

[6] Torres J, Tao L, Xiao L, et al. Experimental Study on Hydrodynamics of a FPSO in Deep-draft Gulf of Mexico[C]//Ocean, Offshore and Artic Engineering. 2015 : OMAE2015-41514

[7]Wei Yue-Feng, Yang Jian-Ming, Chen Gang, et al. Numerical and Model Test Study on the Hydrodynamic Performance of FDPSO with Spreading Mooring System[J]. Journal of Ship Mechanics , 2012 , 16(6):603-616.

[8]Wei Yue-Feng, Yang Jian-Ming, Chen Gang, et al.Numerical and model research on the hydrodynamic performance of FDPSO with 
single point mooring system[J]. Journal of Ship Mechanics , 2014, 18(4):395-405.

[9] Sun Qiang, Dong Qing-hui, Peng Gui-sheng, et al. Taut mooring system design and analysis of Octagon FDPSO[J], Ocean engineering equipment and technology, 2015, 2(3):175-183.

[10]Wei Yue-Feng, Yang Jian-Ming, Chen Gang, et al.Research on the concept design for deep-water multi-column semi-submersible FDPSO[J]. The Ocean Engineering , 2011, 29(1):1-8.

[11]Li Yan, Tang You-Gang, Zhao Zhi-Juan, et al. Concept Design and Analysis of the Mooring System for the New Type of Multi-Tubular FDPSO [J]. Chinese Journal of Ship Research ，2013， 8(5):97-103.

[12]Zhao Zhi-Juan.Concept Design and Research on the Hydrodynamic Performance of a Multi-Cylindrical FDPSO[D]; Tianjin : Tianjin University, 2012

[13]Tang You-Gang, Zhang Su-Xia, Zhang Ruo-Yu, et al. Advance of study on dynamic characters of mooring systems in deep water[J]. The Ocean Engineering, 2008, 26(1): 120-126.

[14]Zhang Huo-Ming. Investlgation on hybrid model testing technique of deep-sea platforms based on equivalent water depth truncation[D].Shanghai: Shanghai Jiao Tong University, 2005.

[15]Zhang Huo-Ming, Yang Jian-Min, Xiao Long-Fei. Investigation on optimization design of equivalent water-depth truncated mooring system in hybrid model testing[J]. The Ocean Engineering, 2006, 24(2): 7-13.

[16]Yang Jian-Ming, Xiao Long-Fei, Sheng Zhen-Bang. Experimental study on hydrodynamics of Marine Engineering[M].Shanghai: Publishing House of Shanghai Jiao Tong University , 2008.1-136.

[17]API-RP-2SK, Design and Analysis of Station keeping Systems for Floating Structures (third Edition), American Petroleum Institute, October 2005

Xuncheng Tu Postgraduate of Naval Architecture and Ocean Engineering department of Jiangsu University of Science and Technology, China. +8618344815748

Xianghong Huang Phd of Harbin Engineering University, China. $+8618706100669$

Chunyang Zhao Postgraduate of Naval Architecture and Ocean En-gineering department of Jiangsu University of Science and Technology, China. +8618796087050 